\title{
Políticas territoriais e financiamentos públicos. 0 BNDES a serviço de quem?
}

Territorial policies and public financing. What's the use of the BNDES?

Politiques territoriales et financements publics. Le BNDES, à quoi ça sert?

\section{Gilberto Oliveira da Silva Junior}

\section{(2) OpenEdition}

\section{Journals}

\section{Edição electrónica}

URL: http://journals.openedition.org/espacoeconomia/142

DOI: 10.4000/espacoeconomia.142

ISSN: 2317-7837

\section{Editora}

Núcleo de Pesquisa Espaço \& Economia

\section{Refêrencia eletrónica}

Gilberto Oliveira da Silva Junior, «Políticas territoriais e financiamentos públicos. O BNDES a serviço de quem? », Espaço e Economia [Online], 2 | 2013, posto online no dia 09 março 2013, consultado o 15 novembro 2019. URL : http://journals.openedition.org/espacoeconomia/142 ; DOI : 10.4000/ espacoeconomia. 142

Este documento foi criado de forma automática no dia 15 novembro 2019

(C) NUPEE 


\section{Políticas territoriais e}

\section{financiamentos públicos. O BNDES a serviço de quem?}

Territorial policies and public financing. What's the use of the BNDES?

Politiques territoriales et financements publics. Le BNDES, à quoi ça sert?

\section{Gilberto Oliveira da Silva Junior}

\section{Introdução}

1 Nas últimas décadas o estado brasileiro vive transformações profundas que possibilitam um sincero amadurecimento nas execuções de políticas nacionais. Desde o processo de democratização, passando pelo período neoliberal até o atual estágio, onde política e economia apresentam-se mais articulados, o estado brasileiro evolui em diversas áreas, inclusive na social. Contudo, uma questão, fortemente interligada, parece, ainda, negligenciada de discussões fundamentais para se alcançar o âmago de um desenvolvimento nacional consistente.

Os aparelhos do estado brasileiro ainda não trabalham coerentemente com a lógica territorial, necessária a qualquer país, principalmente, um de dimensões continentais. A tese que o Estado perdeu toda a força de organização dos territórios e, principalmente, nas circulações dos fluxos de integração espacial, não se confirma devido a uma série de ações que exemplificam a manutenção e a reestruturação deste poder. Todavia, estas ações parecem ainda, priorizar uma lógica do capital em vez de uma lógica territorial (ARRIGHI, 1996), haja vista uma série de ações do Banco Nacional de Desenvolvimento Econômico e Social - BNDES.

O presente trabalho tem o objetivo de apresentar a força do Estado brasileiro nas políticas de ordenamento territorial através de uma das instituições com maior influência em importantes setores, como o industrial e o de infra estrutura. A análise busca o entendimento do BNDES como um possível indutor da política nacional de 
desconcentração produtiva e, por conseguinte, da desconcentração de desenvolvimento econômico e social.

4 Esta política de desconcentração regional baseia-se nas intensas desigualdades existentes entre as macro regiões brasileiras, construídas ao longo de décadas de investimentos que corroboraram as diferenças econômicas e sociais. O próprio BNDES é um dos responsáveis pelo incremento das desigualdades regionais ao longo da segunda metade do século XX.

5 Com o intuito de compreender a lógica territorial do BNDES foi analisado o período entre 2002 e 2009, quando o governo brasileiro assumiu claramente um discurso de investimentos sociais e de diminuição das desigualdades regionais. Este período foi comparado aos 50 anos de financiamentos do banco ao longo de diferentes políticas nacionais.

\section{Cinquenta anos de ordenamento territorial}

6 Ao longo de 50 anos (1952 - 2002) o BNDES solidificou-se como uma das principais instituições públicas na construção de um ordenamento territorial com bases, na maioria das vezes, em políticas desenvolvimentistas. A importância do BNDES pode ser descrita, de maneira geral, em três pontos:

7 Trata-se de uma instituição pública, nascida e consolidada através de diferentes fontes de recursos provenientes do povo brasileiro, como o imposto de renda, o PIS/PASEP (Programa de Integração Social/Programa de Formação do Patrimônio do Servidor Público) e, atualmente, o FAT (Fundo de Amparo ao Trabalhador). Todos utilizados para financiar diversos setores produtivos que possuem grandes implicações no território nacional.

8 A grandeza alcançada pela instituição ao longo de 50 anos (1952 - 2002), abrindo um enorme leque setorial com possibilidades de financiamentos a partir dos volumosos recursos do banco. Com a soma de $\mathrm{R} \$ 500$ bilhões desembolsados nos 50 anos fica clara a posição do BNDES como um dos principais instrumentos do ordenamento territorial.

O fato de ser uma instituição definida como a principal promotora do desenvolvimento do Brasil, bem como a fonte dos principais programas de ordenamento territorial, como o "Avança Brasil" e o "Programa de Aceleração do Crescimento", que busca concomitante o desenvolvimento e a diminuição das desigualdades regionais.

Contudo, no decorrer dos 50 anos, as transformações não foram muito significativas quando comparamos a desconcentração dos investimentos e diminuição das disparidades espaciais. Do total desembolsado pelo banco estatal, no referido período, o estado de São Paulo foi o grande beneficiário, respondendo sozinho com $30 \%$ do total. Não é por acaso que o estado se apresentou como o grande concentrador da principal região brasileira (Sudeste) nas cinco décadas. Essa concentração paulista torna-se ainda mais efetiva quando percebemos que o Rio de Janeiro, segundo lugar nos financiamentos totais, concentrou $12 \%$ dos recursos do BNDES. Esses dois estados, somados ao estado de Minas Gerais, terceiro colocado, com $11 \%$, sublinham à forte concentração da região sudeste. Com $9 \%$ dos financiamentos, o estado da Bahia apresentou-se como uma espécie de outdoor da região nordeste, sendo claramente um dos estados que apresentou o maior grau de concentração no interior de sua própria região. Pernambuco, que apareceu em segundo lugar na região nordeste, é o único que 
alcançou a taxa de $2 \%$, deixando apenas $1 \%$ para cada um dos outros estados, escamoteando, dessa maneira, a noção de desconcentração regional (SILVA Jr. 2009).

11 Por fim, as regiões norte e centro oeste ficaram restritas a determinados empreendimentos ou setor econômico. A região norte recebe investimentos muito concentrados, principalmente nos setores de infra estrutura como grandes hidrelétricas, que possuem um custo social bem elevado. Já a região centro oeste possui uma dependência crônica do setor agropecuário, pois, quando por motivos diversos climáticos, por exemplo - este setor sofre algum dano, os volumes destinados à região imediatamente tornam-se diminutos. Além da concentração regional, ocorre também uma concentração setorial, que não recebe atenção do poder público para que possa ser revertida.

\section{Novas políticas, antigas concentrações}

O ano de 2002 foi um marco na história política do Brasil com a eleição de Luiz Inácio "Lula" da Silva, um símbolo da classe proletária no país. Além do reforço na democracia brasileira o novo período era desenhado através de uma nova perspectiva econômica e social, haja vista a grande presença de ideólogos que defendiam idéias desenvolvimentistas através do fortalecimento do Estado. A indicação do economista e professor Carlos Lessa para a presidência do BNDES foi um dos principais indicadores das transformações que eram propostas, apesar da mudança no comando do banco em 2005. Esta transformação foi seguida por mudanças na organização interna da instituição, "resultado de uma nova visão de modelo de banco de desenvolvimento" (BNDES, Relatório Anual, p. 28, 2005).

13 Em um período de doze anos com políticas neoliberais (1990 - 2002), houve ênfase na abertura econômica e na diminuição do poder do Estado brasileiro. Esta ênfase ocorreu através do processo de privatizações, onde o BNDES configurou-se também como peça chave, por vezes financiando futuros compradores. Com a eleição de 2002 e o discurso de um "novo" desenvolvimento crio-se grande apreensão nos principais atores do país.

14 Contudo, no BNDES ocorreu uma diminuição no total de investimentos desembolsados no primeiro ano do novo governo. Em 2003 foram desembolsados cerca de $\mathrm{R} \$ 34$ bilhões, ou seja, valor abaixo dos $\mathrm{R} \$ 46$ bilhões em 2002 e dos $\mathrm{R} \$ 36$ bilhões nos anos de 2001 e 2000. Nesta primeira mudança, entre 2002 e 2003, o setor mais afetado foi do de infra estrutura com uma variação negativa de $27 \%$, seguido do setor de educação e saúde com variação negativa de $11 \%$. Já no aspecto regional, a concentração manteve-se no mesmo padrão, ou seja, investimentos que priorizavam a denominada região concentrada (SANTOS, 2000). Observe a tabela a seguir:

Desembolsos do BNDES por regiões brasileiras (em R\$ mil e em percentual)

\begin{tabular}{|l|l|l|l|}
\hline Regiões & 2001 & 2002 & 2003 \\
\hline Norte & $859.696 / 3 \%$ & $1.880 .842 / 5 \%$ & $712.056 / 2 \%$ \\
\hline Nordeste & $3.334 .224 / 13 \%$ & $3.783 .724 / 10 \%$ & $3.112 .239 / 9 \%$ \\
\hline Sudeste & $14.493 .742 / 57 \%$ & $23.073 .648 / 62 \%$ & $20.036 .124 / 60 \%$ \\
\hline
\end{tabular}




\begin{tabular}{|l|l|l|l|}
\hline Sul & $4.825 .463 / 19 \%$ & $6.091 .783 / 16 \%$ & $6.841 .930 / 21 \%$ \\
\hline Centro-Oeste & $1.703 .399 / 7 \%$ & $2.589 .274 / 7 \%$ & $2.831 .241 / 8 \%$ \\
\hline
\end{tabular}

Fonte: Relatório Anual do BNDES - 2003.

15 A tabela apresenta a região concentrada (sudeste e sul) com $76 \%$ dos investimentos em 2001, 78\% em 2002 e com 80\% em 2003, corroborando com a concentração espacial. Já a região nordeste, ícone da desigualdade no Brasil e pólo dos discursos de desconcentração sócio-econômica, sofreu perda, mesmo que pequena. Já a região centro-oeste mostrou-se a mais equilibrada ao longo desses três anos, clarificando uma íntima relação com o setor agropecuário.

Nos anos subseqüentes o valor dos desembolsos seguiu um padrão de crescimento, mesmo em anos de menor crescimento da economia brasileira, ou mesmo no período da crise internacional entre 2008 e 2009 (NASSIF, 2006). Neste aspecto a prática se igualava ao discurso fazendo com que um dos principais indutores do financiamento econômico e social aumentasse sua participação na grande diversidade de setores econômicos. Cabe mencionar, que os retornos dos investimentos do BNDES também batiam recordes no montante de capital acumulado pela instituição. Desta maneira, o banco foi um dos principais articuladores do Programa de Aceleração da Economia (PAC), principal programa do governo federal na consecução de um desenvolvimento econômico gradativo e sustentável. O gráfico a seguir apresenta a evolução dos desembolsos do BNDES no período estudado.

Desembolsos do BNDES no período 2002 - 2010 (em bilhões).

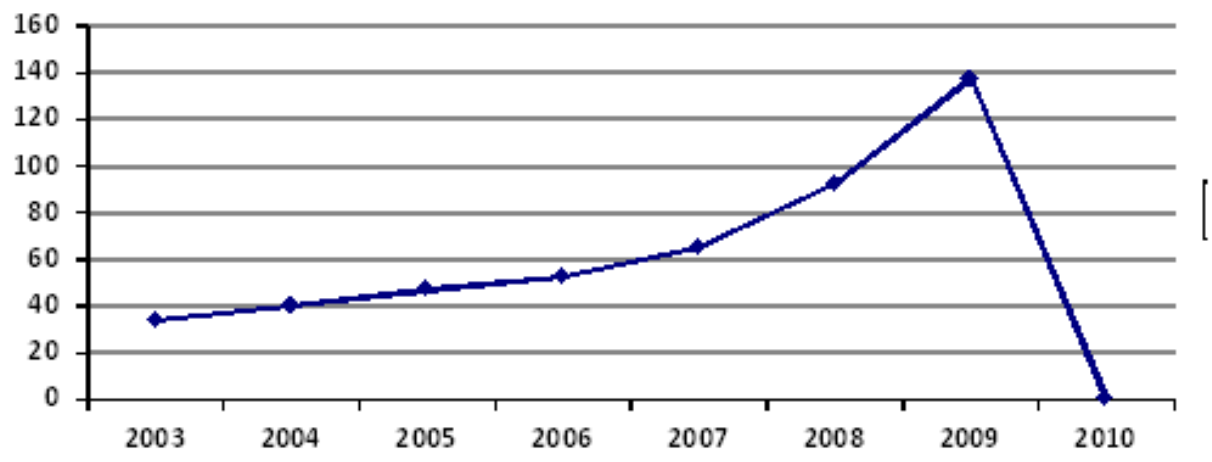

FONTE: RELATÓRIO ANUAL DO BNDES $(2003$ - 2009)

17 Apesar do elevado crescimento nos valores desembolsados pela instituição, a desconcentração produtiva manteve-se tímida, sem maiores transformações com os períodos anteriores. A manutenção desta estrutura é sempre apoiada no argumento dos setores produtivos, com ênfase ao setor industrial. No biênio 2004 / 2005 o volume de investimentos para o setor industrial possuiu uma variação positiva de 49\%, configurando-se com cerca de 50\% dos desembolsos do BNDES em 2005. Os setores de comércio/serviços obteve variação positiva de $22 \%$ seguido pelo setor de infra estrutura com variação positiva de $13 \%$. O único setor, dentre os principais, que retrocedeu foi o 
agropecuário com variação negativa de $41 \%$. Tal variação negativa refletiu diretamente nos volumes destinados a região centro-oeste, como explicitado no relatório de 2004: "Quanto à região Centro-Oeste, a explicação para a queda nas aprovações também deve ser atribuída às condições climáticas adversas, que reduziram fortemente os investimentos da região." (BNDES [Relatório Anual], 2004, p.24).

O sudeste que, historicamente, sempre foi a região mais privilegiada no volume dos investimentos e por isso possui um maior peso na estrutura industrial do país, continuou a liderar os desembolsos do banco neste período. Desta forma, a região sudeste obteve efetivo crescimento de investimentos, saindo dos $\mathrm{R} \$ 21$ bilhões em 2004 para $\mathrm{R} \$ 28,7$ bilhões em 2005 , representando uma variação positiva de $35 \%$. Na mesma toada apresentou-se a região sul; enquanto em 2004 a região foi beneficiada com $\mathrm{R} \$ 8,7$ bilhões em 2005 obteve a soma de cerca de $\mathrm{R} \$ 10$ bilhões, ou seja, variação positiva de $10 \%$. Já as regiões norte e centro-oeste obtiveram variações negativas de $17 \%$ e $37 \%$, respectivamente. Como já referido, este desempenho, principalmente da região centrooeste deixa claro a dependência desta área com o setor agropecuário.

Contudo foi significativa a variação positiva da região nordeste em $39 \%$, a maior registrada neste período. A região saltou de $\mathrm{R} \$ 2,5$ bilhões em 2004 para $\mathrm{R} \$ 3,9$ bilhões em 2005. Neste caso, podemos observar uma perspectiva de transformação, ainda que incipiente e, sobretudo, já registrada em períodos anteriores. Em estudos anteriores (SILVA JR., 2009) tal crescimento já foi observado, todavia, a sua manutenção não perdurou mais do que alguns poucos anos. Além disso, ocorreu significativa concentração no interior da região, como é o caso do estado da Bahia que sempre acumulou mais da metade dos investimentos direcionados para a referida região.

o padrão de investimentos segue praticamente o mesmo, talvez com o setor de infra estrutura caracterizando a principal transformação, haja vista o seu efetivo incremento, praticamente igualando-se ao setor industrial no volume de desembolsos (NASSIF, 2006). O Programa de Aceleração do Crescimento (PAC) configura-se como instrumento condutor do crescimento deste setor, sendo dividido nas seguintes áreas: Energia, Logística, Social \& Urbano e Administração Pública. Foi também através do PAC o maior incremento de investimentos inter regionais, respondendo com $10 \%$ de todo o investimento diretamente relacionado com o PAC. Cabe ressaltar, que no ano de 2008 do total de $\mathrm{R} \$ 92$ bilhões desembolsados pelo BNDES $\mathrm{R} \$ 23$ bilhões estavam diretamente relacionados com o Programa de Aceleração da Economia.

21 Nos três últimos anos de governo do presidente Luiz Inácio Lula da Silva as conformações regionais pouco foram alteradas. Este fato iluminou o descompasso entre os discursos desenvolvimentistas e a prática de uma das principais instituições com função de desenvolvimento regional igualitário, como pode ser observado na tabela a seguir.

Desembolsos do BNDES no período 2008 - 2010 (em bilhões e em percentual).

\begin{tabular}{|l|l|l|l|}
\hline Regiões & 2008 & 2009 & 2010 \\
\hline Norte & $5.345 .289 / 5 \%$ & $11.267 .003 / 8 \%$ & $11.748 .089 / 7 \%$ \\
\hline Nordeste & $7.600 .345 / 9 \%$ & $22.102 .188 / 16 \%$ & $17.211 .537 / 10 \%$ \\
\hline
\end{tabular}




\begin{tabular}{|l|c|c|c|}
\hline Sudeste & $51.647 .345 / 56 \%$ & $71.720 .571 / 52 \%$ & $97.971 .472 / 58 \%$ \\
\hline Sul & $17.457 .201 / 19 \%$ & $20.969 .817 / 16 \%$ & $30.126 .402 / 18 \%$ \\
\hline Centro Oeste & $9.902 .473 / 10 \%$ & $10.712 .520 / 7 \%$ & $11.367 .289 / 7 \%$ \\
\hline
\end{tabular}

Fonte: Boletim Trimestral do BNDES - 2009 / 2010

22 As informações clarificam a manutenção de uma configuração espacial concentrada, mesmo com um significativo aumento dos investimentos em setores como o de infraestrutura. Contudo, o setor industrial continua a liderar o total de desembolsos do BNDES. A região concentrada, a mais importante no processo produtivo industrial, mantêm uma elevada porcentagem de investimentos, tendo no ano de 2009 a menor concentração com $68 \%$ dos desembolsos do banco. Foi também neste ano que a região nordeste atingiu a maior quantidade de investimentos, igualando-se, percentualmente, a região sul. Cabe ressaltar, que entre os financiamentos para a região nordeste, destaca-se a linha de crédito para o GASENE, que formado por uma ligação de gasodutos entre as regiões nordeste e sudeste.

23 Já no ano de 2010, os investimentos para a região concentrada atingem um elevado patamar, resultando no retorno, já anunciado, da região nordeste para um volume inferior ao da região sul. Já as regiões centro oeste e norte são tradicionalmente dependentes de alguns setores, como o agropecuário e o de energia, respectivamente.

\section{A concentração do capital}

24 A partir da concentração espacial dos financiamentos concedidos pelo BNDES, existe outra forma de concentração espacial que, na maioria das vezes, encontra-se à sombra dos dados preliminares. Significa dizer que o financiamento de uma grande empresa no Nordeste pode esconder um dado de concentração extremamente desigual no processo de ordenamento territorial: a concentração do capital. A empresa financiada em regiões pouco beneficiadas pode na verdade ser inteiramente ligada às empresas das regiões mais beneficiadas e desenvolvidas. Esta prática, por vezes, foi incentivada para que o processo de modernização atingisse as áreas mais deficientes.

Dessa forma, a simples alocação das empresas subsidiárias seria motivo de alarde, principalmente pelos governos locais, de inserção destas áreas ao mundo do progresso e da modernidade. Ocorreu uma ampla instalação de fábricas nas regiões menos favorecidas, aproveitando-se de inúmeros benefícios, tais como mão de obra mais barata, recursos naturais e, principalmente, isenções ficais. Este fato corroborou com a "guerra dos lugares", onde os principais beneficiados são as grandes empresas em detrimento, na maioria das vezes, do espaço que as recebe.

Esta idéia se torna mais nítida ao destacar a distribuição espacial dos 300 maiores Grupos Empresariais que atuam no território brasileiro. 
Distribuição Espacial dos 300 maiores Grupos no Brasil

\begin{tabular}{|l|l|l|l|}
\hline UF & GRUPOS & UF & GRUPOS \\
\hline SP & 137 & CE & 04 \\
\hline RJ & 48 & AL & 03 \\
\hline DF & 06 & AM & 02 \\
\hline MG & 26 & RN & 01 \\
\hline ES & 06 & MS & 01 \\
\hline PR & 14 & GO & 01 \\
\hline BA & 09 & PB & 01 \\
\hline RS & 29 & PA & 01 \\
\hline SC & 11 & & \\
\hline
\end{tabular}

Fonte: Gazeta Mercantil, Anuário 2006.

A partir da tabela podemos tecer as seguintes considerações: em primeiro lugar, a grande concentração, em números absolutos, nos estados do Sudeste, que mais uma vez são encabeçados por São Paulo. Esta unidade da federação mantém sua supremacia aglutinando mais do que o dobro de grupos existentes no estado do Rio de Janeiro. Estes dois estados somados com Minas Gerais alocam mais de 200 grupos do total de 300, confirmando o poder econômico da região. O Espírito Santo aparece mais uma vez bem aquém da média da região. Os estados da região sul corroboram o seu poderio aglutinando 54 grupos, bem como sua relativa igualdade interna, estabelecendo uma diferença de apenas 18 grupos entre o Rio Grande do Sul, primeiro da região, e Santa Catarina, terceiro da região. Já a região nordeste apresenta mais uma vez a Bahia como estado com a maior concentração, sendo que todos os demais estados alcançam, somados, a mesma quantidade de 9 grupos.

Sendo assim, a distribuição dos 300 maiores grupos vai de encontro com a distribuição dos financiamentos do BNDES. Os dois dados mostram a ampla concentração mantida pela região sudeste, tendo São Paulo também como principal beneficiário, bem como apontam para a concentração na Bahia, confirmando a idéia que o BNDES financiou um milagre econômico baiano (SILVA JR., 2004, p. 176). Será que essa semelhança dos dados é meramente casualidade.

$\mathrm{Na}$ evolução dos cerca de 60 anos de atuação do BNDES, duas características sublinham o processo de pseudodescentralização e aumento da concentração do poder financeiro. A primeira é a forte concentração econômica e política exercida por pontos específicos do país, notoriamente consolidados em São Paulo, Rio de Janeiro e Brasília. A segunda é que a partir da década de 90 do século XX existe o acirramento da concentração capitalista em poucos grupos. Estes grupos, historicamente, foram beneficiados com o modelo capitalista de desenvolvimento implementado no Brasil a luz da concepção de tripé produtivo. Todavia, o "pé" do Estado brasileiro é vislumbrado como mantenedor de um status quo onde o capital privado, como os Grupos Camargo Correa e Votorantim são os grandes beneficiados. 

cada vez mais atento as inovações capitalistas: o estamento. O Brasil patrimonialista (FAORO, 2001) perdura ao longo dos anos, bem como das novas configurações do Estado. 0 estamento pode ser compreendido também como uma "nova" classe social, segundo João Bernardo (BERNARDO, 1991), a classe dos gestores. Esta classe não possui um lugar fixo atuando concomitantemente na iniciativa privada e no poder público. Independentemente, contudo, de onde os gestores atuam, a lógica seguida se faz muito próxima, havendo inclusive uma plotagem das atuações, que resulta em uma nova aliança entre classes. Neste sentido, os gestores da iniciativa privada traçam estratégias a fim de aumentarem suas áreas de ações, mantendo o poder decisório agregado em seletos pontos. Geralmente, tais pontos são as unidades da federação detentoras de força econômica. Os gestores localizados nos aparelhos do Estado, no caso aqui o BNDES, administram os recursos de maneira a garantir a concentração do poder através de uma lógica do capital e sempre escamoteado pelo argumento desenvolvimentista.

\section{Considerações finais}

O Brasil possui a tradição de pensar o seu desenvolvimento, prioritariamente, nos grandes projetos nacionais, negligenciando que, muitas vezes, a grandiosidade do desenvolvimento poderia ser pensada a partir de soluções consideradas pequenas, porém muito mais igualitárias. Os grandes projetos nacionais transformaram-se muitas vezes em uma territorialidade alienígena, apropriada por seletivos grupos econômicos (SANTOS, 2000). Na maioria das vezes quem se beneficia desses grandes projetos são unicamente as grandes corporações, seja do setor de mineração, química, celulose ou mesmo as empreiteiras, que lucram valores exorbitantes a partir da demanda criada e dos créditos disponibilizados.

O período analisado (2003 - 2010) de investimentos do BNDES ressalta a manutenção territorial construída ao longo de mais de 50 anos de atuação da instituição. Mesmo com toda a transformação política ocorrida no período, com ênfases no aumento da participação do estado na política social e econômica do país, a configuração espacial manteve-se a mesma. A desconcentração econômica ainda não ocorreu e a instituição que possui uma real importância na indução do desenvolvimento do Brasil mostra-se ainda ineficiente no papel de propor novas configurações regionais. Tal ineficiência é sublinhada quando, repetidamente, é indicado nos estudos do BNDES (relatórios anuais, boletins, informes, dentre outros) a sua função de descentralização dos investimentos, como é descrito na seguinte ideia: "Além disso, o banco deve ser um instrumento democrático de crédito, acessível também às micro, pequenas e médias empresas e às regiões menos favorecidas do país, de modo que possa ser efetivamente o "Banco do Desenvolvimento de Todos os Brasileiros"." (BNDES [Relatório Anual] 2005, p.28).

Outra análise que cabe aprofundamento são os atores que mais se beneficiam com os investimentos, bem como a ampliação da atuação do banco. Iniciado somente como indutor de restritas áreas, atualmente o BNDES possui um leque de investimentos que ultrapassam as fronteiras territoriais brasileiras. A apropriação dos volumosos recursos públicos - FAT - requer uma discussão urgente sobre o Estado brasileiro e sua lógica territorial. Os Donos do Poder são cada vez mais persuasivos na conquista de novos espaços, seja no território brasileiro, seja no interior dos aparelhos estamentais. Creio 
ser fundamental o engajamento de maior parcela da sociedade nas discussões críticas sobre desenvolvimento que se pretende.

A Geografia não deve negligenciar a análise de importantes atores, como o BNDES, na construção de um modelo de ordenamento territorial do Brasil extremamente seletivo, direcionado basicamente para os detentores de poder político e econômico. Por isso, é de fundamental importância procurar entender essa geografia do poder, de maneira que, com consciência, busquem-se alternativas mais igualitárias de desenvolvimento sócio-espacial.

\section{BIBLIOGRAFIA}

ARRIGHI, Giovanni. O longo século XX. São Paulo: Unesp, 1996.

BERNARDO, João. Economia dos conflitos sociais. São Paulo: Cortez, 1991.

BNDES. Relatório Anual. Rio de Janeiro, 2002.

Relatório Anual. Rio de Janeiro, 2003.

Relatório Anual. Rio de Janeiro, 2005.

Relatório Anual. Rio de Janeiro, 2006.

Relatório Anual. Rio de Janeiro, 2008.

. Boletim Trimestral. Área de Pesquisa e Acompanhamento Econômico. Rio de Janeiro, n 1, 2007.

. Boletim Trimestral. Área de Pesquisa e Acompanhamento Econômico. Rio de Janeiro, n 6, 2009.

. Boletim Trimestral. Área de Pesquisa e Acompanhamento Econômico. Rio de Janeiro, n 10, 2010.

LESSA, Carlos. 15 anos de política econômica. São Paulo: Brasiliense, 1982.

NASSIF, André. Há evidências de desindustrialização no Brasil? BNDES, textos para discussão, Rio de Janeiro, 2006.

SANTOS, Milton, SILVEIRA, Maria. L. O Brasil: território e sociedade no início do século XXI. Rio de Janeiro / São Paulo: Record, 2000.

SILVA JR., Gilberto Oliveira da. BNDES: 50 anos de ordenamento do território brasileiro. In: SILVEIRA, M, LAMOSO, L, MOURÃO, P.(org). Questões Nacionais e Regionais. São Paulo: Expressão Popular: Unesp, 2009.

\section{RESUMOS}

O Banco Nacional de Desenvolvimento Econômico e Social (BNDES) é um dos principais agentes do financiamento público no Brasil e, por conseguinte, interfere diretamente nas políticas 
territoriais do país. O presente trabalho tem o objetivo de analisar espacialmente os desembolsos do BNDES no período 2002-2010, comparando-os com os cinquenta anos anteriores de investimentos. A despeito da recente tendência à desconcentração, tal como revelada pela Região Nordeste, em termos históricos é possível constatar a intensa concentração na Região Sudeste sobretudo em São Paulo e no Rio de Janeiro, colocando em xeque a função de desconcentração regional proclamada pela instituição.

The Brazilian Economic and Social Development Bank (BNDES) is one of the most important agents for public financing in Brazil, consequently, it directly interferes in the national territorial policies. This paper aims to analyze in terms of space the BNDES outlays between 2002-2010 and comparing them to the investments made fifty years before. In spite of the recent tendency for decentralization, as it is revealed in the Northeast region, in historical terms, it is possible to find an intense concentration of investments in the southeast region of the country, particularly in São Paulo and Rio de Janeiro, raising questions about the regional decentralization role proclaimed by the institution.

Dans cet article, on analyse les déboursements régionaux du BNDES pendant la période 2002-2010, en les comparant avec les derniers cinquante ans d'investissements. En dépit de la récente tendance à la déconcentration telle qu'on peut l'apercevoir à partir de la Région Nordest, le processus historique montre une intense concentration dans la Région Sud-est, surtout à São Paulo et à Rio de Janeiro. Cela remet en cause la déconcentration régionale proclamée par le propre BNDES.

\section{ÍNDICE}

Keywords: BNDES, territorial policies, publics investments, regional question, regional desconcentration

Mots-clés: BNDES, politiques territoriales, financements publics, question régionale, déconcentration régionale

Palavras-chave: BNDES, políticas territoriais, financiamentos públicos, questão regional, desconcentração regional

\section{AUTOR}

\section{GILBERTO OLIVEIRA DA SILVA JUNIOR}

Mestre em Geografia pela Universidade Federal Fluminense. Professor de Geografia do Instituto Gay Lussac 